\title{
Down-Regulation of TRPM8 in Pulmonary Arteries of Pulmonary Hypertensive Rats
}

\author{
Xiao-Ru Liuu, ${ }^{a, c, d}$ Qing Liu, ${ }^{a, c, d}$ Gai-Ying Chen ${ }^{a, c}$ Ying Hu ${ }^{a, c}$ James S.K. Sham ${ }^{b, c}$ \\ Mo-Jun Lin ${ }^{\mathrm{a}, \mathrm{c}}$
}

aDepartment of Physiology and Pathophysiology, Fujian Medical University, Fuzhou, Fujian Province, People's Republic of China; 'Division of Pulmonary and Critical Care Medicine, Johns Hopkins University School of Medicine, Baltimore, Maryland, USA; 'Laboratory of Cardiovacular Sciences, Fujian Medical

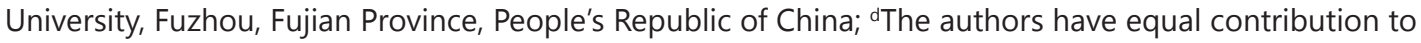
this publication

\section{Key Words}

Transient receptor potential melastatin - Pulmonary hypertension - Calcium signaling • Monocrotaline $\cdot$ Chronic hypoxia $\cdot$ Menthol

\begin{abstract}
Background: Pulmonary hypertension $(\mathrm{PH})$ is characterized by profound vascular remodeling and alterations in $\mathrm{Ca}^{2+}$ homeostasis in pulmonary arterial smooth muscle cells (PASMCs). Multiple transient receptor potential melastatin-related (TRPM) subtypes have been identified in vascular tissue. However, the changes in the expression and function of TRPM channels in pulmonary hypertension have not been characterized in detail. Methods: We examined the expression of TRPM channels and characterized the functions of the altered TRPM channels in two widely used rat models of chronic hypoxia $(\mathrm{CH})$ - and monocrotaline (MCT)-induced $\mathrm{PH}$. Results: $\mathrm{CH}$-exposed and $\mathrm{MCT}$-treated rats developed severe $\mathrm{PH}$ and right ventricular hypertrophy, with a significant decrease in TRPM8 mRNA and protein expression in pulmonary arteries (PAs). The downregulation of TRPM8 was associated with significant reduction in menthol-induced cation-influx. Time-profiles showed that TRPM8 down-regulation occurred prior to the increase of right ventricular systolic pressure (RVSP) and right ventricular mass index (RVMI) in $\mathrm{CH}$-exposed rats, but these changes were delayed in MCT-treated rats. The TRPM8 agonist menthol induced vasorelaxation in phenylephrine-precontracted PAs, and the vasorelaxing effects were significantly attenuated in PAs of both PH rat models, consistent with decreased TRPM8 expression. Conclusion: Downregulation of TRPM8 may contribute to the enhanced vasoreactivity in $\mathrm{PH}$.

Copyright $\odot 2013$ S. Karger AG, Basel
\end{abstract}

\section{Introduction}

Pulmonary hypertension ( $\mathrm{PH})$ is characterized by profound vascular remodeling, right ventricular hypertrophy and alterations in $\mathrm{Ca}^{2+}$ homeostasis in pulmonary arterial smooth 
muscle cells (PASMCs) [1]. It is associated with a board spectrum of diseases with different pathological features and etiological mechanisms. They are classified into five categories, namely, pulmonary arterial hypertension (PAH), $\mathrm{PH}$ owing to left heart disease, $\mathrm{PH}$ owing to lung disease and/or hypoxemia, chronic thromboembolic pulmonary hypertension, and $\mathrm{PH}$ with unclear multifactorial mechanisms [2]. The etiological mechanisms of the various forms of PH are different, but they all have the common features of abnormalities in pulmonary vascular function, vascular cell proliferation, and remodeling, suggesting that they may share some important signaling mechanisms in the development of the disease.

$\mathrm{Ca}^{2+}$ signaling plays vital roles in regulation of numerous physiological and pathophysiological processes, including contraction, proliferation, hypertrophy and migration of PASMCs [3]. Previous studies indicate that there are major alterations in ion channel expression and $\mathrm{Ca}^{2+}$ homeostasis, such as membrane depolarization, downregulation of voltage-gated $\mathrm{K}^{+}$channels, upregulation of canonical transient receptor potential (TRPC) channels, increase in $\mathrm{Ca}^{2+}$ influx, and elevation of resting intracellular $\mathrm{Ca}^{2+}$ concentration $\left(\left[\mathrm{Ca}^{2+}\right]_{\mathrm{i}}\right)$ in PASMCs of idiopathic PAH patients and animal models of PH [4-8]. $\mathrm{Ca}^{2+}$ influx in PASMCs is mainly regulated by voltage-dependent $\mathrm{Ca}^{2+}$ channels (VDCC) and voltageindependent nonselective cation channels.

Members of transient receptor potential (TRP) gene family are known to encode different types of nonselective cation channels. They play critical roles in numerous cellular functions activated by a wide variety of chemical and physical stimuli including agonist, mechanical stress, temperature, light and sound to modulate calcium influx. To date, 28 mammalian TRP homologues have been found in a wide variety of cells and tissues, and at least 10 TRPs have been identified as functional channels in vascular smooth muscle cells (VSMCs) [9]. They are involved in many different vascular functions, such as myogenic response, agonist-induced vasoconstriction, VSMCs proliferation, and vascular remodeling.

The canonical TRP (TRPC) channels have been implicated as store-operated calcium entry (SOCC) and receptor-operated calcium entry (ROCC) in vascular smooth muscle cells. The expression of TRPC1 and TRPC6 mRNAs and proteins are upregulated, and SOCE and ROCE are potentiated in PASMCs of hypoxic PAH rats [4]. Furthermore, expression of TRPC1 and SOCE are also enhanced in PASMCs of MCT-induced PH rats [8]. These results suggest that TRPC1-SOCE may be a common signaling pathway for the development of PH. Compared to TRPC, the physiological roles of other TRP subfamilies are much more elusive in pulmonary vascular smooth muscle. A recent study shows that the vanilloid related TRP (TRPV4) channel operates as a mechanosensitive cation channel in PASMCs, and the expression of TRPV4 channel is upregulated in PAs of chronic hypoxic rats [10]. Moreover, the upregulation of TRPV4 in PAs is associated with the appearance of myogenic tone, and deletion of TRPV4 gene delayed and suppressed the development of PH.

The melastatin TRP subfamily, which consists of eight mammalian members (TRPM18), are known to participate in tumor suppression, reactive oxygen species (ROS)-induced apoptosis, $\mathrm{Mg}^{2+}$ homeostasis, and thermo-sensing (hot and cold) in nonvascular tissues [1113]. A few recent studies have revealed that some of these TRPM channels are expressed and may play different physiological roles in vascular smooth muscles [10, 14-15]. It has been proposed that TRPM4 contributes to membrane depolarization and vasoconstriction associated with increased intraluminal pressure in cerebral arteries [16-18]. TRPM7 was identified as a functional regulator of $\mathrm{Mg}^{2+}$ homeostasis in mouse and rat mesenteric and aortic smooth muscle cells [19]. Application of the TRPM8-specific agonist menthol or icilin induced small vasoconstriction in relaxed vessels, but caused vasodilation in endotheliumdenuded rat tail arteries pre-contracted with $\mathrm{KCl}$ or the $\alpha$-adrenoceptor agonist phenylephrine (PHEN) [15]. We have previously shown that TRPM2, TRPM3, TRPM4, TRPM7 and TRPM8 were expressed in intralobar pulmonary arteries (PAs) and aorta of rats, and TRPM8 was the most abundantly expressed TRPM subtype [14]. Activation of TRPM8 channels in PASMCs with menthol induced robust increase in $\left[\mathrm{Ca}^{2+}\right]_{i}$ which could be abolished by removal of extracellular $\mathrm{Ca}^{2+}$ or by applying the non-selective cation channel blocker $\mathrm{Ni}^{2+}$. These results indicate that multiple functional TRPM channels are expressed in rat intralobar PAs and 
these novel $\mathrm{Ca}^{2+}$ entry pathways may play important roles in the regulation of pulmonary and systemic circulation.

However, alternations of the expression and function of TRPM channels in PH have not been studied in detail [10]. The present study used two classical rat models of chronic hypoxia-induced PH and MCT-induced PH to examine the changes in the expression and functional activities of TRPM channels, and to explore their contribution to the development of PH.

\section{Materials and Methods}

\section{PH models}

Chronic hypoxia $(\mathrm{CH})$-induced pulmonary hypertension was produced by the established method. Male Sprague-Dawley rats (200 250g) were placed in a hypoxic chamber and exposed to either normoxia or normobaric hypoxia for $3 \sim 4$ weeks. The chamber was continuously flushed with either room air or a mixture of room air and $\mathrm{N}_{2}$ to maintain oxygen level at $10 \%$. Chamber $\mathrm{O}_{2}$ and $\mathrm{CO}_{2}$ were monitored continuously (OM-11 oxygen analyzer). Rats were exposed to room air for $10 \mathrm{~min}$ twice a week to clean the cages, and to replenish food and water supplies. MCT-induced PAH were generated in adult male Sprague-Dawley rats (200 250g). Rats were given a single intraperitoneal injection of MCT $(60 \mathrm{mg} / \mathrm{kg})$ or an equivalent volume of saline $(2 \mathrm{ml} / \mathrm{kg}$ ). MCT (Sigma) was dissolved in $1 \mathrm{M} \mathrm{HCl}$, neutralized to $\mathrm{pH} 7.4$ with $1 \mathrm{M} \mathrm{NaOH}$, and diluted with saline [8]. Twenty-one days after MCT injection, rats in the MCT and sham injection groups were anesthetized with urethane $(1 \mathrm{~g} / \mathrm{kg})$. Right ventricle systolic pressure (RVSP) and mean systemic arterial pressure (MSAP) were measured by accessing the right ventricle through the jugular vein and right carotid artery, respectively, using polyethylene catheters connected to pressure transducers (YPJ01; Chengyi, China). Pressure signals were displayed continuously on an RM6240 polygraph (Chengyi, China). Heart rate was determined from the right ventricle pressure pulse. At the end of hemodynamic measurement, the rat was sacrificed with an overdose of urethane. The heart was removed, and right ventricular mass index (RVMI) was calculated as the ratio of wet weight of the right ventricle to the left ventricular wall plus septum $[\mathrm{RV} /(\mathrm{LV}+\mathrm{S})]$. In the experiment on the time-course of change of TRPM8 expression and PH development, animals were sacrificed on $0,1,3,5,7,14$, and 21 days after exposure to $\mathrm{CH}$ exposure or MCT treatment. All procedures were approved by the Animal Care and Use Committee of Fujian Medical University.

Isolation and culture of PASMCS

PASMCs were enzymatically isolated and transiently cultured as previously described [8]. Briefly, male Sprague-Dawley rats were injected with heparin and anesthetized with sodium pentobarbital (130mg/ kg i.p.). They were exsanguinated and the lungs were removed and transferred to a petri dish filled with HEPES-buffered salt solution (HBSS) containing (in mM) $130 \mathrm{NaCl}, 5 \mathrm{KCl}, 1.2 \mathrm{MgCl}_{2}, 1.5 \mathrm{CaCl}_{2}, 10 \mathrm{HEPES}$, 10 glucose, $\mathrm{pH} 7.4$ (adjusted with $\mathrm{NaOH}$ ). Third and fourth generation intrapulmonary arteries $(\sim 300$ to $800 \mu \mathrm{m}$ ) were isolated and cleaned free of connective tissue. The endothelium was removed by gently rubbing the luminal surface with a cotton swab. Arteries were then allowed to recover for 30 min in cold $\left(4^{\circ} \mathrm{C}\right) \mathrm{HBSS}$, followed by $20 \mathrm{~min}$ in reduced-Ca ${ }^{2+}(20 \mu \mathrm{M})$ HBSS at room temperature. The tissue was digested at $37^{\circ} \mathrm{C}$ for $20 \mathrm{~min}$ in $20 \mu \mathrm{M} \mathrm{Ca}^{2+} \mathrm{HBSS}$ containing collagenase (Type I, $1750 \mathrm{U} / \mathrm{ml}$ ), papain $(9.5 \mathrm{U} / \mathrm{ml}$ ), bovine serum albumin $(2 \mathrm{mg} / \mathrm{ml})$, and dithiothreitol $(1 \mathrm{mM})$, then removed and washed with $\mathrm{Ca}^{2+}$-free HBSS to stop digestion. PASMCs were gently dispersed by trituration with a small-bore pipette in $\mathrm{Ca}^{2+}$-free HBSS at room temperature. The cell suspension was then placed on 25mm glass coverslips in Ham's F-12 medium (with L-glutamine) supplemented with $0.5 \%$ fetal calf serum, $100 \mathrm{U} / \mathrm{ml}$ of streptomycin, and $0.1 \mathrm{mg} / \mathrm{ml}$ of penicillin. PASMCs from chronic hypoxic and normoxic animals were transiently ( 24 hours) cultured inside a modular incubator chamber (billups-rothenberg, Inc.) under $4 \% \mathrm{O}_{2} / 5 \% \mathrm{CO}_{2}$ and $21 \% \mathrm{O}_{2} / 5 \% \mathrm{CO}_{2}$, respectively.

\section{Quantitative real-time RT-PCR}

De-endothelialized PAs frozen in liquid nitrogen were homogenized mechanically. Total RNA was extracted using an RNeasy mini kit (Qiagen, Valencia, CA). Total RNA (1 $\mu \mathrm{g}$ ) was used for first-strand cDNA synthesis using Prime Script reverse transcriptase kit (DRR037A, Takara, Japan) according to the 
Liu et al.: TRPM8 in Hypoxia- and MCT-Induced Pulmonary Hypertension

\begin{tabular}{|c|c|c|c|}
\hline Gene & & Oligonucleotide Primers & Product(bp) \\
\hline \multirow[t]{2}{*}{ TRPM1 } & Sense & 5'-CCTCCTGTGGACACCAAAGT-3' & \\
\hline & Antisense & 5'-AAGACAAGAGCGTCCAGCAT-3' & 144 \\
\hline \multirow[t]{2}{*}{ TRPM2 } & Sense & 5'-CCATGCCACACATCAAACTC-3' & \\
\hline & Antisense & 5'-ATGATGGCCCAAATGAGAAG-3' & 121 \\
\hline \multirow[t]{2}{*}{ TRPM3 } & Sense & 5'-ACCGGGTTGACTTTGTGAAG-3' & \\
\hline & Antisense & 5'-CAGATGAAGGGTGTTTGGT-3' & 105 \\
\hline \multirow[t]{2}{*}{ TRPM4 } & Sense & 5'-ACCGGGTTGACTTTGTGAAG-3' & \\
\hline & Antisense & 5'-GCAGATGAAGGGTGTTTGGT-3' & 141 \\
\hline \multirow[t]{2}{*}{ TRPM5 } & Sense & 5'-GGCACACCCATCTTACGACT-3' & \\
\hline & Antisense & 5'-ACTGTCTGGCTCCTGCAGAT-3' & 126 \\
\hline \multirow[t]{2}{*}{ TRPM6 } & Sense & 5'-AAGCCATCCTGTCACCAAAG-3' & \\
\hline & Antisense & 5'-CAAAGAGGTAGACGGCTTGC-3' & 180 \\
\hline \multirow[t]{2}{*}{ TRPM7 } & Sense & 5'-GGAAGGTGTGTGCAAAATGA-3' & \\
\hline & Antisense & 5'-GCTTCAGGTCCTTCACAAGC-3' & 136 \\
\hline \multirow[t]{2}{*}{ TRPM8 } & Sense & 5'-GCTACGGACCAGCATTTCAT-3' & \\
\hline & Antisense & 5'-GCTTGTCAATGGGCTTCTT-3' & 172 \\
\hline \multirow[t]{2}{*}{$\beta$-actin } & Sense & 5'-CCCATCTATGAGGGTTACGC-3' & \\
\hline & Antisense & 5'-TTTAATGTCACGCACGATTTC-3' & 150 \\
\hline
\end{tabular}

Table 1. Oligonucleotide sequences of the primers used for RT-PCR

manufacturer's protocol. Quantitative real-time RT-PCR was used to quantify the changes in the expression of TRPM subtypes. PCR reactions were set up with iQ SYBR Green PCR Supermix (Bio-Rad, Hercules, CA) (Roche, Germany) using $0.25 \mu \mathrm{l}$ of cDNA as the template in each $10 \mu \mathrm{l}$ reaction mixture. Gene-specific realtime PCR primers for TRPM channels are listed in Table 1. The PCR protocol, consisting of an initial step at $95^{\circ} \mathrm{C}$ for $10 \mathrm{~min}$, followed by 40 cycles at $95^{\circ} \mathrm{C}$ for $15 \mathrm{~s}, 60^{\circ} \mathrm{C}$ for $1 \mathrm{~min}$, and $72^{\circ} \mathrm{C}$ for $1 \mathrm{~min}$, was performed using the Multicolor Real-Time PCR Detection System (ABI, USA). In the experiments for determining the time course of change in TRPM8 expression, the relative quantities of TRPM8 were calculated using the $\triangle \mathrm{CT}$ method with $\beta$-actin as the internal control. TRPM8 values measured from samples at various time points were normalized to the averaged value of the control samples.

\section{Western blot analysis}

De-endothelialized PAs were quickly frozen in liquid nitrogen. The frozen tissues were crushed and homogenized using a mortar and pestle and then resuspended in ice-cold cell lysis buffer containing $50 \mathrm{mM}$ Tris-HCl (pH 7.4), $150 \mathrm{mM} \mathrm{NaCl}, 1 \%$ deoxycholic acid, $0.1 \%$ SDS, $0.5 \%$ Nonidet P- 40 , and protease inhibitor cocktail (Roche, Mannheim, Germany). The homogenate was centrifuged at $4^{\circ} \mathrm{C}$ and $14,000 \mathrm{~g}$ for $15 \mathrm{~min}$, then the supernatant was collected, and the protein concentration was estimated using the bicinchoninic acid assay. The protein sample $(40 \mu \mathrm{g})$ was resolved in an $8 \%$ SDS-PAGE and electrotransferred onto a PVDF membrane. The membrane was blocked with $5 \%$ (wt/vol) nonfat dry milk in TBS containing $0.05 \%$ Tween 20 (TBST) for $2 \mathrm{~h}$ at room temperature, followed by incubation at $4^{\circ} \mathrm{C}$ overnight with a monoclonal antiTRPM8 antibody (ACC-049, 1:300 dilution; Almone). The PVDF membrane was then washed with TBST. After being washed, the membrane was incubated with goat-anti-rabbit secondary antibody (no. 7074, 1:5000 dilution; Cell Signaling Technology) at room temperature for $1 \mathrm{~h}$. Excess secondary antibody was 
Liu et al.: TRPM8 in Hypoxia- and MCT-Induced Pulmonary Hypertension

washed again, the bound secondary antibody was detected with enhanced chemiluminescence (Pierce, Rockford, IL), and images were taken using a Gel Logic 200 image system (Kodak, New Haven, CT).

\section{Isometric contraction}

Intralobar PAs ( 300 to $800 \mu \mathrm{m})$ were isolated and placed in oxygenated modified Kreb's solution containing (in mM) $118 \mathrm{NaCl}, 4.7 \mathrm{KCl}, 1.2 \mathrm{MgCl}_{2}, 10$ HEPES, 11.1 dextrose, and $2.0 \mathrm{CaCl}_{2}$. They were cleaned of connective tissue and cut into $4 \mathrm{~mm}$ lengths. Endothelium was disrupted by gently rubbing the lumen with a small wooden stick, and the arterial rings were suspended between two stainless steel stirrups in organ chambers filled with modified Kreb's solution for isometric tension recording. The solution was gassed with $95 \% \mathrm{O}_{2}+5 \% \mathrm{CO}_{2}$ to maintain a $\mathrm{pH}$ of 7.4 and the temperature at $37^{\circ} \mathrm{C}$. Isometric contraction was measured using a strain gauge connected to a polygraph. Resting tension was adjusted to $0.8 \sim 1.0 \mathrm{~g}$. Arteries were exposed to $60 \mathrm{mM} \mathrm{KCl}$ to establish maximum contraction and to phenylephrine $\left(3 \times 10^{-7} \mathrm{M}\right)$ followed by acetylcholine $\left(10^{-6} \mathrm{M}\right)$ to verify complete disruption of endothelium.

\section{$\mathrm{Mn}^{2+}$ quenching of Fura-2}

Rate of $\mathrm{Ca}^{2+}$ entry through TRPM8 was quantified by quenching of fura- 2 with $\mathrm{Mn}^{2+}$. PASMCs from control, CH- and MCT-treated rats were loaded with fura-2AM as described above. Fura- 2 was excited at the $\mathrm{Ca}^{2+}$-insensitive isobestic point of $360 \mathrm{~nm}$, and emission light was recorded at $510 \mathrm{~nm}$ (PTI, USA). PASMCs were then bathed in a $\mathrm{Ca}^{2+}$ free (with $0.1 \mathrm{mM}$ EGTA) Tyrode solution containing $10 \mu \mathrm{M}$ nifedipine. After a

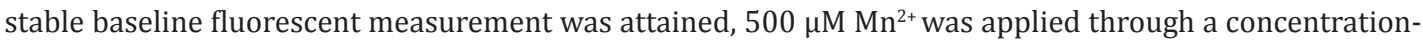
clamp system with the multi-barrel pipette positioned $<50 \mu \mathrm{m}$ from PASMCs. The rates of quenching of fura2 fluorescence in PASMCs with/without drug treatments were determined and compared.

\section{Statistical analysis}

Data are expressed as means $\pm \mathrm{SE}$, and $n$ indicates the number of animals, cell samples, or PA rings used. Statistical significance was assessed using unpaired or paired Student's t-tests and ANOVA wherever appropriate. Differences were considered significant at $\mathrm{P}<0.05$. Curve fitting was performed using the SigmaPlot11.0 software.

\section{Results}

Verification of CH- and MCT-induced PH models

$\mathrm{CH}-$ and MCT-treated rats exhibited profound $\mathrm{PH}$ and right ventricular hypertrophy when examined 3 weeks after hypoxia exposure or MCT injection, respectively. PH was generally more severe in the MCT-treated rats. RVSP increased by two-folds in CH-exposed rats, and almost tripled in MCT-treated rats (control: $25.1 \pm 0.9 \mathrm{mmHg}, n=29$; MCT: $60.6 \pm 4.2$ mmHg, $n=18, \mathrm{P}<0.01$, CH: $52.6 \pm 3.2 \mathrm{mmHg}, n=14$; $P<0.01$ ). RVMI was about $40 \%$ higher for $\mathrm{CH}$ rats and was nearly doubled in MCT rats when compared with that of normoxic controls (control: 27.5 $\pm 0.5 \%, n=29$; MCT: $59.9 \pm 4.9 \%, n=18, \mathrm{P}<0.01$, CH: $38.5 \pm 0.7 \% ; n=14, P<0.01$ ) (Fig. 1, $A$ and $B$ ). Consistent with previous reports, there were no significant changes in mean SAP (control: $104.0 \pm 3.6 \mathrm{mmHg}$; MCT: $102.5 \pm 3.4 \mathrm{mmHg}$; $\mathrm{CH}$ : $101.0 \pm 2.3 \mathrm{mmHg}$ ) and heart rate (control: $395 \pm 15$ beats/min; MCT: $359 \pm 13$ beats/min; $\mathrm{CH}: 361 \pm 7$ beats/min, Fig. $1, C$ and $D$ ) in the three groups of rats. Histological examination of lung sections of CH- and MCTtreated rats showed that the medial wall of the muscular small PAs (vessel outer diameter of $<100 \mu \mathrm{m}$ ) was thickened significantly (data not shown).

\section{TRPM8 expression was downregulated in PAs of CH- and MCT-induced PH rats}

The relative mRNA expression of various TRPM subtypes was determined using quantitative real-time RT-PCR. TRPM1-8 transcripts were detected in endothelium-denuded PAs isolated from control rats. TRPM7 $(0.018 \pm 0.005)$ and TRPM8 $(0.010 \pm 0.003)$ transcripts were predominantly expressed, with a lower level of TRPM2, TRPM3, TRPM4 and TRPM6 transcripts, and almost no expression of TRPM1 and TRPM5 in control PAs. Expression of various TRPM channels was unchanged in PAs of $\mathrm{CH}$ - and MCT-treated rats, except for 
Fig. 1. Validation of pulmonary hypertension in chronic hypoxia $(\mathrm{CH})$ and monocrotaline (MCT)treated rats. $(A)$ Mean right ventricular pressure (RVSP), $(B)$ right ventricular hypertrophy indexed by RVMI, (C) mean systemic arterial pressure (MSAP) and $(D)$ heart rate $(\mathrm{HR})$ in control, MCT-treated and $\mathrm{CH}$-induced rats. The numbers of animals used in the control, MCT, and $\mathrm{CH}$ groups were 29,18 , and 14 , respectively. ** $\mathrm{P}<0.01$, difference between control and $\mathrm{PH}$ experimental model (MCT or $\mathrm{CH}$ ); \#\# $\mathrm{P}<0.01$, difference between MCT and $\mathrm{CH}$ groups.

Fig. 2. Alterations in transient receptor potential melastatin (TRPM) expression in pulmonary arteries (PAs) of CH-exposured and MCT-treated rats. (A) quantitative real-time RT-PCR analysis of TRPM mRNA expression in endothelium-denuded PAs of control (CON), MCT-treated and $\mathrm{CH}$-exposured rats $(\mathrm{n}=9) ;(B)$ Western blots of TRPM8 protein in PAs of CON, MCT- and CH-induced $\mathrm{PH}$ rats $(\mathrm{n}=9)$; $(C)$ normalized amount of TRPM8 proteins in PAs from 9 samples in CON, MCT and $\mathrm{CH}$ groups. ${ }^{*}$, and $* *$ denote significant differences of $\mathrm{P}<0.05$ and $\mathrm{P}<0.01$, respectively, between control rats and $\mathrm{PH}$ experimental models.
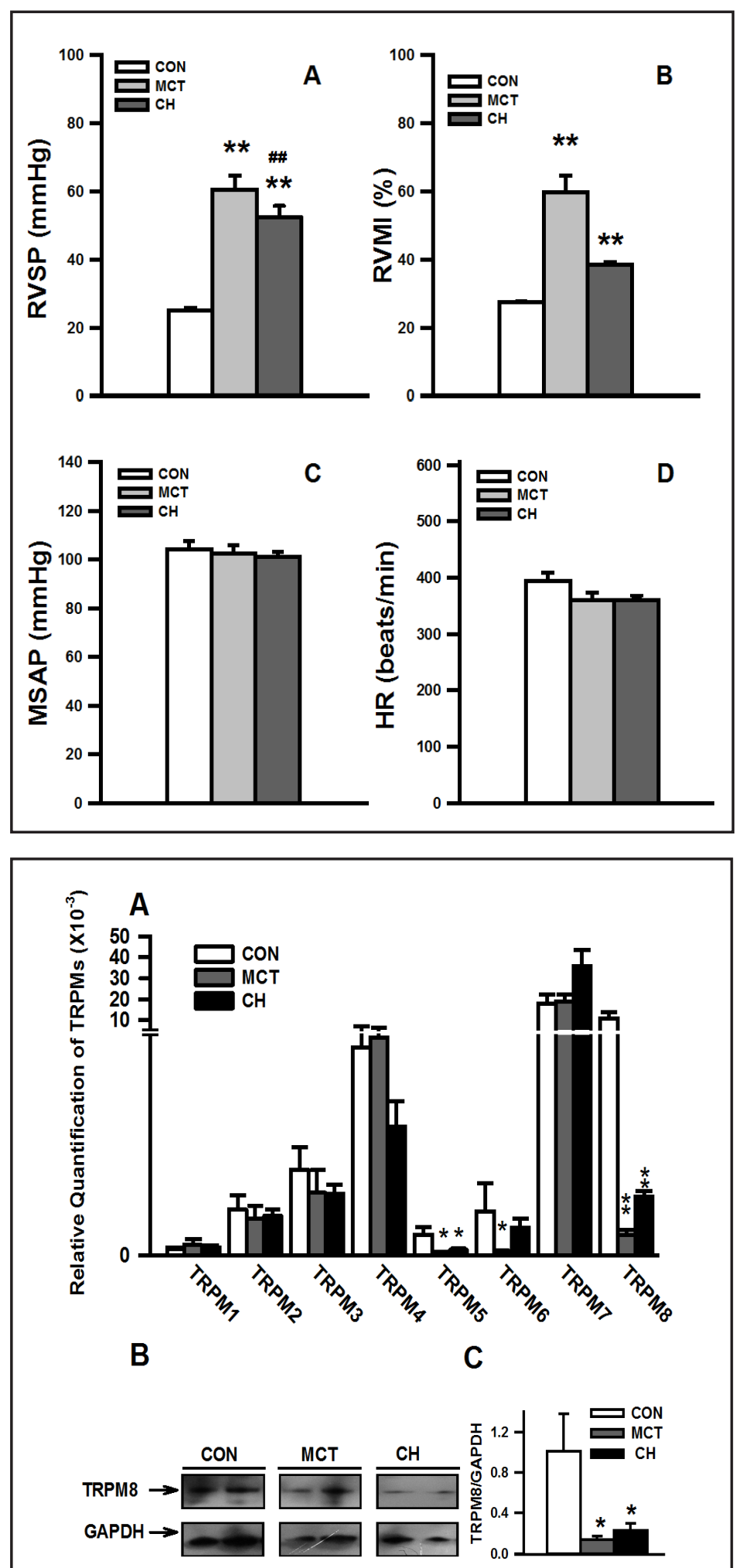

TRPM8. (Fig. 2). Compared to control, $\mathrm{CH}$ and MCT-treatment dramatically suppressed TRPM8 mRNA expression (control: 0.010 $\pm 0.003, \mathrm{n}=9$; MCT: 0.005 $\pm 0.0001, \mathrm{n}=5, \mathrm{P}<0.01$; CH: $0.0015 \pm 0.002, \mathrm{n}=9, \mathrm{P}<0.01$ ). Consistent with mRNA results, TRPM8 protein level relative to GAPDH was also significantly decreased in both CH- and MCT-treated PAs (Fig. 2, B and C). 


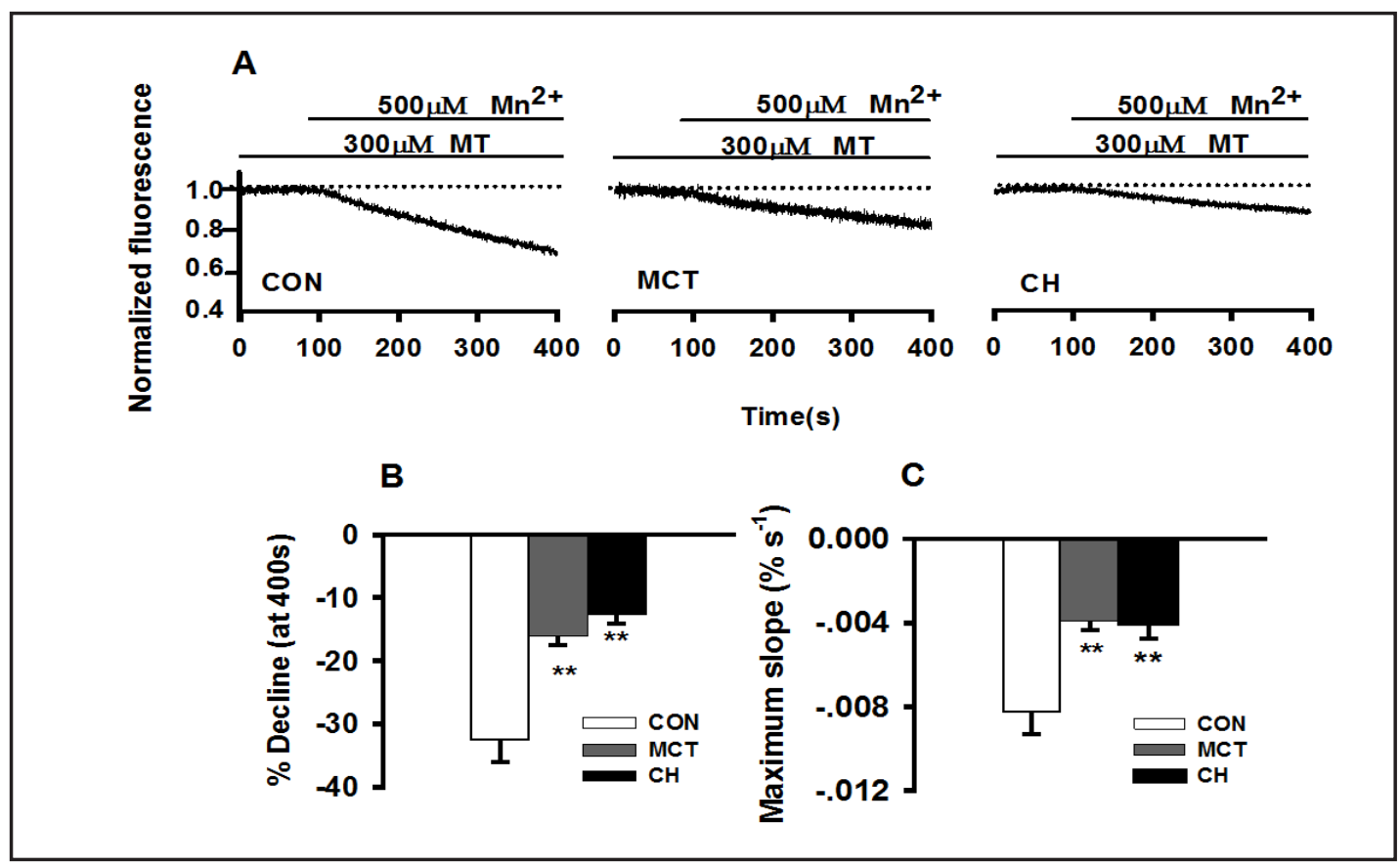

Fig. 3. Characterization of MT-induced cation entry by $\mathrm{Mn}^{2+}$ quenching of fura-2 in PASMCs. (A) Representative tracings recorded in control, MCT- and CH-treated PASMCs. The averaged maximum quenching at 400s $(B)$ and average maximum rate of quenching $(C)$. 10 to 12 experiments from at least 3 different animals were performed for each group. ** indicates significant difference between control and PASMCs from $\mathrm{CH}$ - or MCT-treated rats.

TRPM8-mediated cation entry was reduced in PASMCs of CH and MCT-treated rats

Down-regulation of TRPM8 mRNA and protein in both models PASMCs were accompanied by a reduction in TRPM8-mediated cation entry determined by $\mathrm{Mn}^{2+}$ quenching of fura-2 fluorescence. Activation of TRPM8-mediated cation entry by exposing PASMCs to $300 \mu \mathrm{M}$ menthol for 15 minutes caused a dramatic increase in the rate of $\mathrm{Mn}^{2+}$-induced quenching. The percent reduction in Fura-2 fluorescence measured $300 \mathrm{sec}$ after application of $500 \mu \mathrm{M} \mathrm{Mn}^{2+}$ and max slope of $\mathrm{Mn}^{2+}$-induced quenching was decreased from $-32.6 \pm 3.4 \%$ and $-8.28 \pm 1.05 \times 10^{-3} /$ second $\left(n=10\right.$, Fig. 3 ) in control to $-12.6 \pm 1.5 \%$ and $-4.03 \pm 0.47 \times 10^{-}$ 3 second $(\mathrm{n}=12, \mathrm{P}<0.01$, Fig. 3$)$ in hypoxic PASMCs, and $-16.1 \pm 1.4 \%$ and $-3.91 \pm 0.72 \times 10^{-3} /$ second $(n=10, P<0.01$, Fig. 3$)$ in MCT-treated PASMCs. These results clearly indicate that the expression and the functional activity of TRPM8 channel were both reduced in PASMCs of $\mathrm{CH}-$ or MCT-treated rats.

Time-course of TRPM8 downregulation and the development of pulmonary hypertension in $\mathrm{CH}$ - and MCT-treated rats

The association between TRPM8 expression and PH was further examined by determining TRPM8 mRNA level, RVSP and RVMI in PAs at different time-points after MCT injection or CH exposure (Fig. 4). In PAs of MCT-treated rats, TRPM8 mRNA level decreased after 7 days post-injection and eventually declined to the minimal level after 2 weeks $(0.06 \pm 0.02, n=6, P<0.01$, Fig. 4, A). Significant increase in RVSP and RVMI was observed 3 to 5 days after MCT injection $(36.5 \pm 3.1 \mathrm{mmHg}, \mathrm{n}=13, \mathrm{P}<0.01$, and $30.7 \pm 2.8 \%, \mathrm{n}=11, \mathrm{P}<0.05$, Fig. 4, B and C), and they continued to increase to $60.6 \pm 4.2 \mathrm{mmHg}(\mathrm{n}=16, \mathrm{P}<0.01$, Fig. 4 , B) and 59.9 $\pm 4.9 \%$, ( $n=14, \mathrm{P}<0.01$, Fig. $4, \mathrm{C})$, respectively, after 3 weeks. In contrast, TRPM8 mRNA level decreased significantly on the first day of $\mathrm{CH}$ exposure (normoxia: $1.00 \pm 0.2$, $\mathrm{CH}: 0.08 \pm 0.01, \mathrm{n}=6, \mathrm{P}<0.01$, Fig. $4, \mathrm{D}$ ), and the reduced level was maintained throughout 
Fig. 4. Time-courses of change in TRPM8 mRNA expression, RVSP and RVMI in $\mathrm{CH}$ - and MCT-treated rats. $(A)$ and $(D)$ show the relative quantity of normalized TRPM8 mRNA expression in PA of rats isolated at various timepoints after $\mathrm{CH}$-exposure and MCT injection, respectively. $(B)$ and $(E)$ : average values of RVSP measured at various time-points in the rat models. $(C)$ and $(F)$ : average values of RVMI detected from $\mathrm{CH}$ and MCT rats at various time-points. The data were generated from 6 17 animals in each point, * indicates $\mathrm{P}<0.05$ and $* *$ indicates $\mathrm{P}<0.01$ when comparing with control.

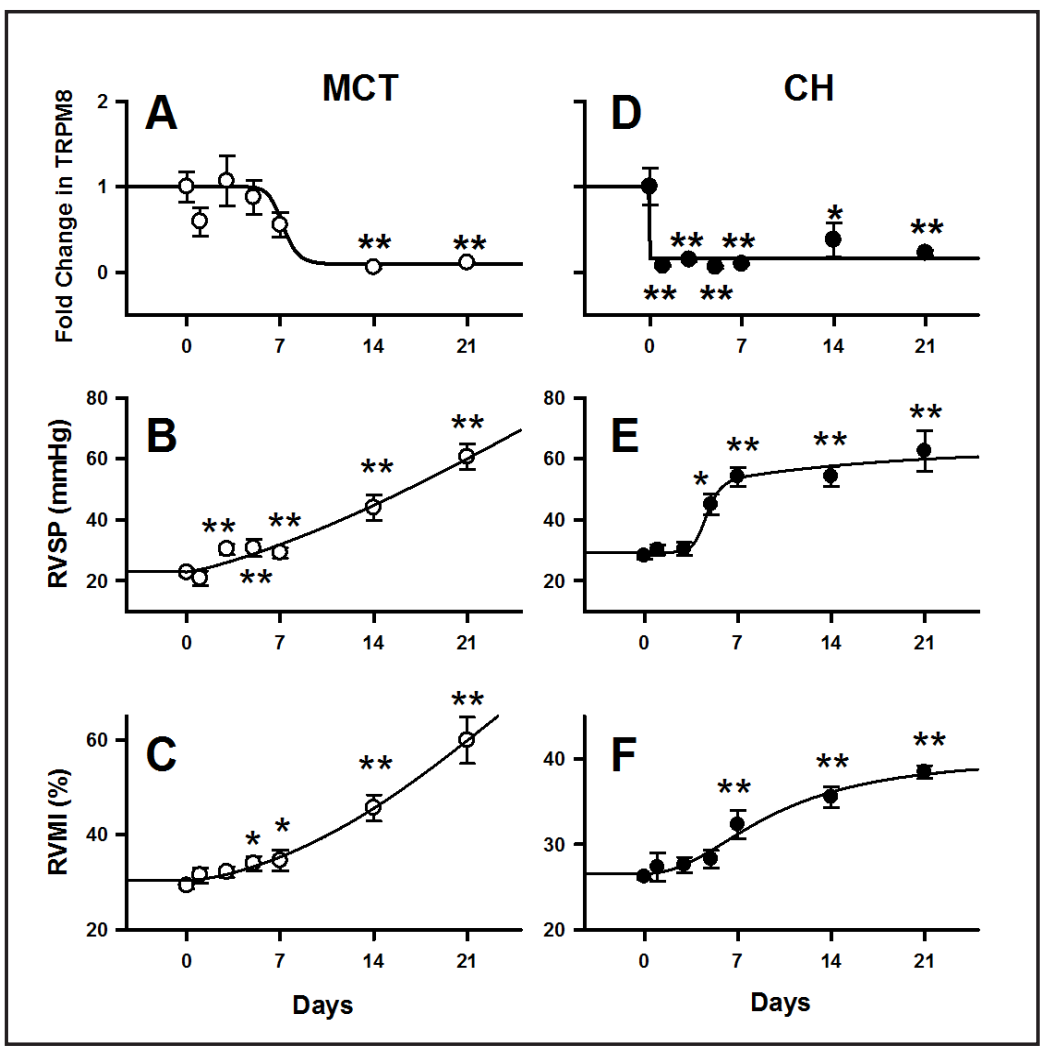

the 3 week period. RVSP increased gradually, reaching a plateau on day 7 and sustained thereafter (Day 0: 27.4 $\pm 1.0 \mathrm{mmHg}, \mathrm{n}=16$; Day 7: 54.2 $\pm 3.1 \mathrm{mmHg}, \mathrm{n}=8, \mathrm{P}<0.01$, Fig. 4, E). The time-course of increase in RVMI was similar to that of RVSP. Significant increase in RVMI was observed in day $7(38.5 \pm 0.7 \%, \mathrm{P}<0.01$, Fig. 4 , F) and it was followed by more gradual increase in the second and third week of $\mathrm{CH}$ exposure. Overall speaking, the downregulation of TRPM8 expression preceded the increase of RVSP and RVMI in CH-treated rats, but slightly lagged behind the changes in RVSP and RVMI in MCT-treated rats.

\section{Menthol-induced vasodilation was attenuated in CH- and MCT-induced PH}

To further evaluate the effect of TRPM8 downregulation on pulmonary vascular function, the vasorelaxant effects of the TRPM8 agonist menthol was determined in phenylephrine pre-contracted endothelium denuded PA rings. Application of $1 \mu \mathrm{M}$ to $3 \mathrm{mM}$ caused concentration-dependent relaxation in PAs of control, CH- or MCT-treated rats. Compared to control PAs, menthol induced vasodilation in phenylephrine pre-contracted PAs was significantly decreased in $\mathrm{CH}$ rats and in MCT rats with the maximal percentage relaxation of $68.2 \pm 2.2 \%(n=13, P<0.01)$ and $70.6 \pm 3.9 \%(n=14, P<0.01)$, respectively (Fig. 5). $\mathrm{EC}_{50}$ of vasodilation was $97.8 \pm 14.7 \mu \mathrm{M}$ in control PAs $(\mathrm{n}=14), 81.5 \pm 14.4 \mu \mathrm{M}$ in PA of MCT-treated rats $(\mathrm{n}=13)$, and $185.0 \pm 41.8 \mu \mathrm{M}(\mathrm{n}=14, \mathrm{P}<0.05$, Fig. 5) in PAs of $\mathrm{CH}$ rats. The attenuated vasorelaxing response of menthol in PAs of $\mathrm{CH}$ - and MCT-treated rats is consistent with of the downregulation of TRPM8 expression in $\mathrm{CH}$ - and MCT-induced PH rats.

\section{Discussion}

In this study, we examined the changes in TRPM mRNA and protein expression as well as their functions in PAs of two widely used rat models of PH. The major findings of this study are: (1) among the various TRPM channels expressed in PAs, TRPM8 was the only 
Fig. 5. Menthol-induced the concentration-dependent inhibition of $1 \mu \mathrm{M}$ phenylephrine (PHEN) pre-contracted de-endothelialized PAs in control, MCT- and $\mathrm{CH}$ - treated rats. $(A),(B)$ and $(C)$ representative concentration-dependent relaxation traces caused by menthol on $1 \mu \mathrm{M}$ PHEN pre-contracted PAs in control, MCT and $\mathrm{CH}$ rats, respectively. Tension is expressed as a percentage of the contractile response induced by $60 \mathrm{mM}$ KCl. (D) Average percent inhibition of PHEN-induced contractions caused by various concentrations of menthol in PAs of control, MCT and $\mathrm{CH}$ rats. $(E)$ and $(F)$ are the averaged $\mathrm{EC}_{50}$ and averaged maximum percent inhibition of PHEN-induced contractions caused by menthol. Arrows indicate the appli-

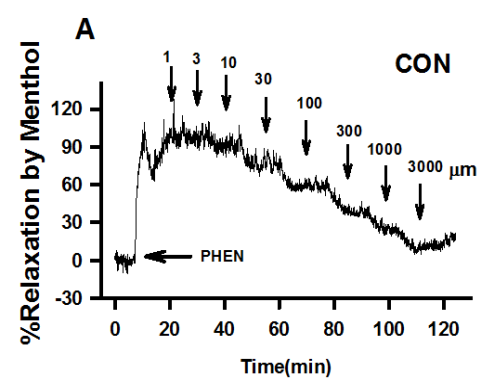

C

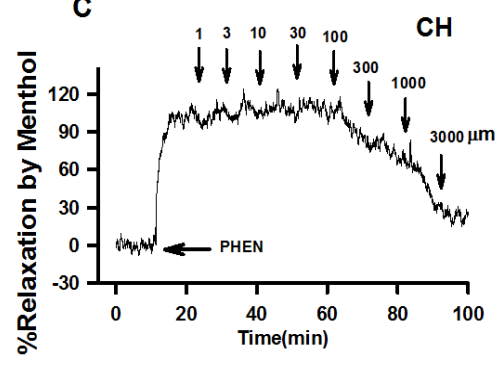

E

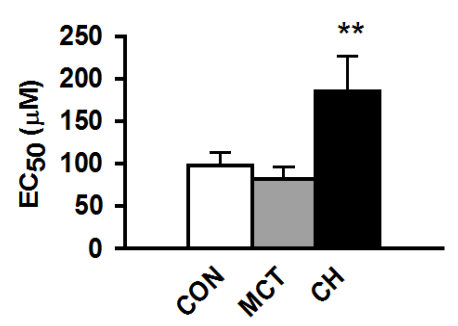

\section{B}

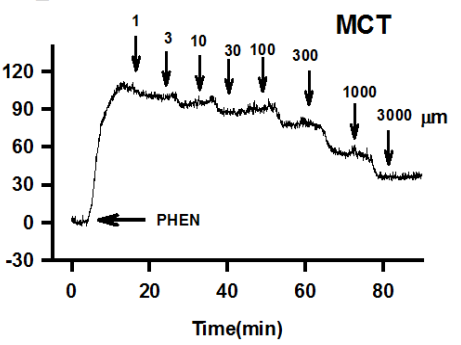

D

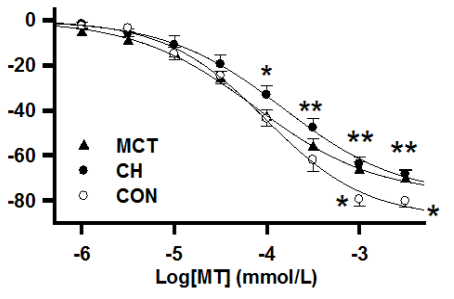

$\mathbf{F}$

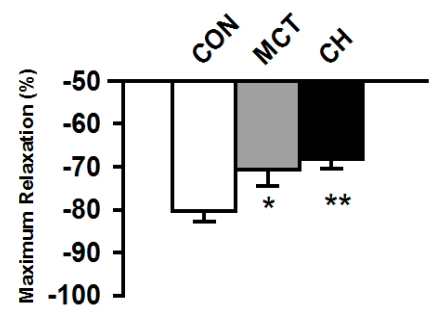

cation of menthol at various concentrations. 13 to 14 experiments from at least 3 different animals were performed for each group, * indicates $\mathrm{P}<0.05$, and ** indicates $\mathrm{P}<0.01$ comparing to the control group.

channel subtype decreased significantly in both PH models; (2) the down-regulation in the expression of TRPM8 mRNA and protein in PASMCs of both models were accompanied by a decline in menthol-induced cation entry; (3) significant down-regulation of TRPM8 mRNA was observed PAs of rats on the first day of $\mathrm{CH}$-exposure and 1-2 weeks after MCTinjection, suggesting that the role of TRPM8 may be different in the development of PH in the two models; (4) the TRPM8 agonist menthol was capable of causing relaxation of deendothelialized PAs and the maximal menthol-induced vasodilatation was reduced in the $\mathrm{CH}-$ and MCT-treated rats compared to those of control groups. These findings provide the molecular and pathophysiological evidence suggesting that TRPM8 may play a contributing role in the development of $\mathrm{CH}$ - and MCT-induced $\mathrm{PH}$.

TRPM8 was originally identified as a prostate-specific gene. Its expression is androgenresponsive and upregulated in human prostate carcinoma [20], suggesting possible involvement in cell proliferation/metastasis. TRPM8 is also a menthol- and cold-sensitive ion channel in sensory neurons for the detection of cold temperature [21, 22]. It has also been shown to be expressed in skeletal and smooth muscle, lungs, bladder and urogenital tract, even though its functions in these tissues are not clear. Functional expression of TRPM8 has been demonstrated in rat intralobar pulmonary arteries and aortic smooth muscle [14]. Menthol elicits significant $\left[\mathrm{Ca}^{2+}\right]_{\mathrm{i}}$ increase in PASMCs and aortic smooth muscle cells. The response could be abolished in the absence of extracellular $\mathrm{Ca}^{2+}$ or in the presence of $\mathrm{Ni}^{2+}$ but was unaffected by nifedipine, suggesting TRPM8 is a functional $\mathrm{Ca}^{2+}$ influx channel in 
vascular myocytes [14]. TRPM8 mRNA and protein were also detected in rat tail, mesentery and femoral arteries [15].

Consistent with our previous studies [10, 14, 23], analysis of TRPM mRNA expression reveals multiple TRPM subtypes are coexpressed in rat PASMCs with TRPM7 and TRPM8 being most abundantly expressed in PAs of normal Sprague-Dawley rats. Among these TRPM subtypes, TRPM8 was the only channel downregulated in PAs of both CH- and MCT-treated rats. Our previous studies indicate that TRPC1, TRPC6 and TRPV4 are upregulated in PAs of $\mathrm{CH}$ rats $[4,10]$ and TRPC1 and TRPC4 expression are increased in PAs of MCT-induced $\mathrm{PH}$ rats [8], resulting in enhanced $\mathrm{Ca}^{2+}$ influx in PASMCs which contributes to the elevated pulmonary vascular tone and resting $\left[\mathrm{Ca}^{2+}\right]_{\mathrm{i}}$, as well as enhanced vascular reactivity in $\mathrm{PH}$ rats. TRPM8 therefore is the first TRP channel recognized by its down-regulation during PH [10], and the decrease in TRPM8 expression is reflected functionally by the significant reduction in non-selective cation entry detected by $\mathrm{Mn}^{2+}$ quenching of Fura- 2 fluorescence.

The association of TRPM8 down-regulation and the development of PH is evident in the time-courses of change in TRPM8 expression and the increase in RVSP and RVMI in the two different experimental models of PH. In the $\mathrm{CH}$ model, significant decrease in TRPM8 mRNA level was observed within one day of hypoxia exposure preceding the significant increase in RVSP and RVMI. This suggests that down-regulation of TRPM8 is an early response to hypoxia and maybe involved in the early development of PH. In contrast, the decrease in TRPM8 expression was considerably delayed in the MCT-model with significant difference observed seven days after MCT injection. This is in line with the slow progressive development of PH in the MCT-model, where MCT is first metabolized into the toxic metabolite MCT pyrrole which causes inflammation, pulmonary endothelial cell damage and apoptosis, medial thickening and adventitial remodeling [24, 25]. Since the reduction in TRPM8 expression was observed after significant increase in RVSP and RVMI, it is likely consequential to the MCT-induced inflammation and cell injury and maybe related to the later stage of pulmonary vascular remodeling. The differences in the time-profiles of change in TRPM8 expression and RVSP in the two models of PH suggest that TRPM8 may participate in CH- and MCT-induced PH in dissimilar manners.

Information on the physiological functions and regulations of TRPM8 in vascular tissue is scant, and how TRPM8 down-regulation contributes to pulmonary hypertension is unclear. Our results showed that the TRPM8 agonist menthol induces concentration-dependent relaxation of phenylephrine-contracted PAs of control, $\mathrm{CH}-$ and MCT-treated rats. This is consistent with a previous report in systemic arteries showing that activation of TRPM8 with menthol or icilin causes a dual effect of small contraction in relaxed arteries but relaxation in vessels precontracted with $\mathrm{KCl}$ or phenylephrine [15]. The relaxation effect was mediated in part through $\mathrm{Ca}^{2+}$-independent phospholipase $\mathrm{A}_{2}$ activation. It has been shown that TRPM8 are localized on plasma membrane and sacroplasmic reticulum [26]. Activation of TRPM8 in plasma membrane may lead to increase in $\mathrm{Ca}^{2+}$ influx to cause vasoconstriction, but it may also activate large conductance $\mathrm{Ca}^{2+}$-activated potassium channels, leading to repolarization of cell membrane as shown in rat tail arterial myocytes [27]. Activation of TRPM8 on sarcoplasmic reticulum membrane, on the other hand, may lead to release/leak of SR $\mathrm{Ca}^{2+}$ and $\mathrm{Ca}^{2+}$ store depletion $[28,29]$. In addition, $\mathrm{Ca}^{2+}$ influx via TRPM8 may also activate $\mathrm{Ca}^{2+}$ activated $\mathrm{Cl}^{-}$channels in PASMCs to cause membrane-depolarization. The balance of these processes determines the manifestation of vasoconstriction or vasodilatation, depending on the vasomotor tone. However, the possible interactions between TRPM8, $\mathrm{Ca}^{2+}$-activated $\mathrm{K}^{+}$and $\mathrm{Cl}^{-}$channels have not been examined, even though the expression of these channels are known to be altered by PH [30-32]. Nevertheless the profound vasorelaxant effect of TRPM8 activated by menthol in PAs suggests that the channel may operate as a regulatory mechanism for counterbalancing vasoconstriction. In this regard, the down-regulation of TRPM8 expression may contribute to the enhanced pulmonary vascular reactivity in PH by reducing the vasodilatory influence against vasoconstriction. This is supported by the significant attenuation in the vasorelaxing effect of menthol observed in phenylephrineprecontracted PAs of CH- and MCT-treated rats. 
Previous studies of TRPM8 in other cell systems showed that TRPM8 is regulated by phosphatidylinositol 4, 5-bisphosphate ( $\mathrm{PIP}_{2}$ ). Direct activation of TRPM8 by PIP ${ }_{2}$ has been demonstrated in purified reconstituted TRPM8 protein in planar lipid bilayers [33-34]. Activation of phospholipase C, as occurs during vasoconstriction induced by many Gq-coupled receptors, can inhibit TRPM8 activity through PIP $_{2}$ hydrolysis/depletion and protein kinase $\mathrm{C}$ dependent mechanisms [35-37]. In addition, TRPM8 is regulation by phospholipaseA2 [38-40]. Lysophospholipids, the end products of $\mathrm{Ca}^{2+}$-independent phospholipaseA2 have been shown to stimulate TRPM8 activity [38, 39]. In CH- and MCT-induced PH, PLC activities are known to be greatly enhanced due to the release of numerous vasoactive agonists and mitogenic factors, as well as the upregulation of many agonist receptors. Hence, it is likely that the channel activity in addition to protein expression of TRPM8 is also greatly reduced in PAs of $\mathrm{PH}$ rats.

In summary, we have demonstrated unequivocally that TRPM8 expression is downregulated in PAs of two etiologically different models of PH. The downregulation of TRPM8 expression is associated with reduced menthol-induced cation entry in PASMCs and menthol-induced vasorelaxation in agonist-precontracted PAs of PH rats. These alterations of TRPM8 expression and functions warrant further detail investigations, which will lead to novel information on the physiological and pathophysiological functions of TRP channels in pulmonary circulation.

\section{Acknowledgements}

This work was supported by grants from the National Natural Science Foundation of China (NSFC 30670772 and NSFC 31171104), and Key Program of Scientific Research of Fujian Medical University (09ZD010) to M.-J. Lin. J.S.K. Sham was supported by NIH grants R01-HL071835 and R01-HL075134.

\section{References}

1 Humbert M, Sitbon 0, Simonneau G: Treatment of pulmonary arterial hypertension. N Engl J Med 2004;351:1425-1436.

2 Simonneau G, Robbins IM, Beghetti M, Channick RN, Delcroix M, Denton CP, Elliott CG, Gaine SP, Gladwin MT, Jing ZC, Krowka MJ, Langleben D, Nakanishi N, Souza R: Updated clinical classification of pulmonary hypertension. J Am Coll Cardiol 2009;54:s43-s54.

3 Berridge MJ, Bootman MD and Roderick HL: Calcium Signaling: dynamics, homeostasis and remodeling. Nat Rev Mol Cel Biol 2003;4:517-529.

-4 Lin MJ, Leung GP, Zhang WM, Yang XR, Yip KP, Tse CM, Sham JSK: Chronic hypoxia-induced upregulation of store-operated and receptor-operated $\mathrm{Ca}^{2+}$ channels in pulmonary arterial smooth muscle cells: a novel mechanism of hypoxic pulmonary hypertension. Circ Res 2004;95:496-505.

5 Mandegar M, Remillard CV, Yuan JX: Ion channels in pulmonary arterial hypertension. Prog Cardiovasc Dis 2002;45:81-114.

6 Yu Y, Fantozzi I, Remillard CV, Landsberg JW, Kunichika N, Platoshyn O, Tigno DD, Thistlethwaite PA, Rubin LJ, Yuan JX: Enhanced expression of transient receptor potential channels in idiopathic pulmonary arterial hypertension. Proc Natl Acad Sci USA 2004;101:13861-13866.

7 Shimoda LA, Sham JSK, Shimoda TH, Sylvester JT: L-type $\mathrm{Ca}^{2+}$ channels, resting $\left[\mathrm{Ca}^{2+}\right]_{\mathrm{i}^{\prime}}$, and ET-1-induced responses in chronically hypoxic pulmonary myocytes. Am J Physiol Lung Cell Mol Physiol 2002;79:L884L894. 
Liu et al.: TRPM8 in Hypoxia- and MCT-Induced Pulmonary Hypertension

8 Liu XR, Zhang MF, Yang N, Liu Q, Wang RX, Cao YN, Yang XR, Sham JS, Lin MJ: Enhanced store-operated $\mathrm{Ca}^{2+}$ entry and TRPC channel expression in pulmonary arteries of monocrotaline-induced pulmonary hypertensive rats. Am J Physiol Cell Physiol 2012;302:C77-C87.

9 Firth AL, Remillard CV, Yuan JX: TRP Channels in Hypertension. Biochim Biophys Acta 2007;1772:895-906.

10 Yang XR, Lin AH, Hughes JM, Flavahan NA, Cao YN, Liedtke W, Sham JS: Upregulation of osmomechanosensitive TRPV4 channel facilitates chronic hypoxia-induced myogenic tone and pulmonary hypertension. Am J Physiol Lung Cell Mol Physiol 2012;302:L555-L568.

11 Valero M, Morenilla-Palao C, Belmonte C, Viana F: Pharmacological and functional properties of TRPM8 channels in prostate tumor cells. Pflugers Arch 2011;461:99-114.

12 Liu Y, Qin N: TRPM8 in health and disease: cold sensing and beyond. Adv Exp Med Biol 2011;704:185-208.

13 Harrington AM, Hughes PA, Martin CM, Yang J, Castro J, Isaacs NJ, Blackshaw LA, Brierley SM: A novel role for TRPM8 in visceral afferent function. Pain 2011;152:1459-1468.

14 Yang XR, Lin MJ, Mcintosh LS, Sham JS: Functional expression of transient receptor potential melastatinand vanilloid-related channels in pulmonary arterial and aortic smooth muscle. Am J Physiol Lung Cell Mol Physiol 2006;290:L1267-L1276.

15 Johnson CD, Melanaphy D, Purse A, Stokesberry SA, Dickson P, Zholos AV: Transient receptor potential melastatin 8 channel involvement in the regulation of vascular tone. Am J Physiol Heart Circ physiol 2009;296:H1868-H1877.

16 Earley S, Waldron BJ, Brayden JE: Critical role for transient receptor potential channel TRPM4 in myogenic constriction of cerebral arteries. Circ Res 2004;95:922-929.

17 Earley S, Straub SV, Brayden JE: Protein kinase C regulates vascular myogenic tone through activation of TRPM4. Am J Physiol Heart Circ Physiol 2007;292:H2613-H2622.

18 Earley S: Vanilloid and melastatin transient receptor potential channels in vascular smooth muscle. Microcirculation 2010;17:237-249.

19 He Y, Yao G, Savoia C, Touyz RM: Transient receptor potential melastatin 7 ion channels regulate magnesium homeostasis in vascular smooth muscle cells: role of angiotensin II. Circ Res 2005;96:207-215.

20 Tsavaler L, Shapero MH, Morkowski S, Laus R: Trpp8, a novel prostate-specific gene, is up-regulated in prostate cancer and other malignancies and shares high homology with transient receptor potential calcium channel proteins. Cancer Res 2001;61:3760-3769.

21 Knowlton WM, McKemy DD: TRPM8: from cold to cancer, peppermint to pain. Curr Pharm Biotechnol 2011;12:68-77.

22 Babes A, Ciobanu AC, Neacsu C, Babes RM: TRPM8, a sensor for mild cooling in mammalian sensory nerve endings. Curr Pharm Biotechnol 2011;12:78-88.

23 Yang XR, Lin MJ, Sham JS: Physiological functions of transient receptor potential channels in pulmonary arterial smooth muscle cells. Adv Exp Med Biol 2010;661:109-122.

24 Wilson DW, Segall HJ, Pan LC, Lamé MW, Estep JE, Morin D: Mechanisms and pathology of monocrotaline pulmonary toxicity. Crit Rev Toxicol 1992;22:307-325.

-25 Stenmark KR, Meyrick B, Galie N, Mooi WJ, McMurtry IF: Animal models of pulmonary arterial hypertension: the hope for etiological discovery and pharmacological cure. Am J Physiol Lung Cell Mol Physiol 2009;297:L1013-1032.

-26 Bidaux G, Flourakis M, Thebault S, Zholos A, Beck B, Gkika D, Roudbaraki M, Bonnal JL, Mauroy B, Shuba Y, Skryma R, Prevarskaya N: Prostate cell differentiation status determines transient receptor potential melastatin member 8 channel subcellular localization and function. J Clin Invest 2007;117:1647-1657.

27 Zholos A, Johnson C, Burdyga T, Melanaphy D: TRPM channels in the vasculature. Adv Exp Med Biol 2011;704:707-729.

28 Bai VU, Murthy S, Chinnakannu K, Muhletaler F, Tejwani S, Barrack ER, Kim SH, Menon M, Veer Reddy GP: Androgen regulated TRPM8 expression: a potential mRNA marker for metastatic prostate cancer detection in body fluids. Int J Oncol 2010;36:443-450.

29 Berkefeld H, Fakler B, Schulte U: $\mathrm{Ca}^{2+}$-activated $\mathrm{K}^{+}$channels: from protein complexes to function. Physiol Rev 2010;90:1437-1459.

30 Sun H, Xia Y, Paudel O, Yang XR, Sham JS: Chronic hypoxia-induced upregulation of Ca2+-activated Clchannel in pulmonary arterial myocytes: a mechanism contributing to enhanced vasoreactivity. J Physiol 2012;590:3507-3521. 
-31 Forrest AS, Joyce TC, Huebner ML, Ayon RJ, Wiwchar M, Joyce J, Freitas N, Davis AJ, Ye L, Duan DD, Singer CA, Valencik ML, Greenwood IA, Leblanc N: Increased TMEM16A-encoded calcium-activated chloride channel activity is associated with pulmonary hypertension. Am J Physiol Cell Physiol 2012;303:C12291243.

32 Dai ZK, Cheng YJ, Chung HH, Wu JR, Chen IJ, Wu BN: KMUP-1 ameliorates monocrotaline-induced pulmonary arterial hypertension through the modulation of $\mathrm{Ca}^{2+}$ sensitization and $\mathrm{K}^{+}$-channel. Life Sci 2010;86:747-755.

33 Zakharian E, Cao C, Rohacs T: Gating of TRPM8 channels activated by cold and chemical agonists in planar lipid bilayers. J Neurosci 2010;30:12526-12534.

-34 Sarria I, Ling J, Zhu M X, Gu JG: TRPM8 acute desensitization is mediated by calmodulin and requires PIP(2): distinction from tachyphylaxis. Neurophysiol 2011;106:3056-3066.

35 Premkumar L S, Raisinghani M, Pingle SC, Long C, Pimentel F: Downregulation of transient receptor potential melastatin 8 by protein kinase C-mediated dephosphorylation. J Neurosci 2005;25:11322-11329.

-36 Linte RM, Ciobanu C, Reid G, Babes A: Desensitization of cold- and menthol-sensitive rat dorsal root ganglion neurones by inflammatory mediators. Exp Brain Res 2007;178:89-98.

37 Abe J, Hosokawa H, Sawada Y, Matsumura K, Kobayashi S: $\mathrm{Ca}^{2+}$-dependent PKC activation mediates menthol-induced desensitization of transient receptor potential M8. Neurosci Lett 2006;397:140-144.

38 Andersson DA, Nash M, Bevan S: Modulation of the cold-activated channel TRPM8 by lysophospholipids and polyunsaturated fatty acids. J Neurosci 2007;27:3347-3355.

39 Gentry C, Stoakley N, Andersson DA, Bevan S: The roles of IPLA2, TRPM8 and TRPA1 in chemically induced cold hypersensitivity. Mol Pain 2010;6:4.

40 Bavencoffe A, Kondratskyi A, Gkika D, Mauroy B, Shuba Y, Prevarskaya N, Skryma R: Complex regulation of the TRPM8 cold receptor channel: role of arachidonic acid release following M3 muscarinic receptor stimulation. J Biol Chem 2011;286:9849-9855. 